\title{
Appraising the ACCC's Caltex-Mobil Decision: An Alternative Measure of Competition Based on Networks
}

\author{
Harry Bloch and Nick Wills-Johnson ${ }^{1}$
}

\section{Abstract}

On 2nd December 2009, the Australian Competition and Consumer Commission (ACCC) announced its intention to oppose the acquisition of Mobil's Australian retail assets by Caltex, based in part on an assessment of the adverse competition effects in some local markets. The proposed merger was subsequently abandoned. The ACCC assessment was based on a standard structural measure of competition, the proportion of petrol stations within each local market that would become controlled by Caltex following such a merger. This paper applies an alternative concept of competition based on the position of each station within a network. Application of the alternative concept to the Perth market, which was excluded from the ACCC analysis, suggests a greater anti-competitive effect from the Caltex-Mobil merger than indicated by application of the standard structural measure of competition.

\section{Introduction}

On 2nd December 2009, the ACCC announced its intention to oppose the acquisition of Mobil's retail network by Caltex, based at least in part on its considerations concerning competitive effects in local markets. ${ }^{2}$ The ACCC deemed such effects likely if the post-merger share of Caltex-controlled outlets in the local market around each Mobil outlet was greater than one-half, and possible if it was greater than 40 per cent.

We suggest a different approach to assessing competitive effects, based upon representing market structure via a network, and looking at the position of each outlet in that network. To our knowledge this approach has not been previously used in assessments made in the application of competition policy, but it is

1 Centre for Research in Applied Economics, Curtin University of Technology, Harry.Bloch@cbs.curtin. edu.au; Nick Wills-Johnson, ACIL Tasman-Perth. Our thanks go to the Editor, William Coleman, and two anonymous referees for helpful comments and suggestions. Responsibility for any errors or omissions rests solely with the authors.

2 Available at http://www.accc.gov.au/content/index.phtml/itemId/904296, which also contains links to the various background papers underpinning the ACCC's decision. 
widely used in geography and mathematical sociology for analogous purposes. We compare the ACCC's approach, based on market shares, with ours, based on position in a network, in a case study of the Perth market. Although the Perth market was not part of the ACCC's investigation, excellent data are readily available. ${ }^{3}$ The focus on a market outside the scope of the ACCC examination means we are not in a position to second-guess the validity of their decision. However, it does allow a clear focus on the application of the alternative approaches to measuring market competitiveness, which is our particular purpose.

In this paper, we outline the ACCC decision in more detail and provide some background to the Perth market. We then show how a network summarising competition can be constructed and provide an overview of the measures that one can use to highlight structural advantage in that network. Following this, we compare our methodology with the ACCC's in the Perth retail petroleum market, before presenting our conclusions.

\section{The ACCC Decision}

The proposed acquisition of Mobil's retail assets by Caltex followed a corporate decision by Mobil to divest much of its downstream business in Australia, part of which involved selling its roughly 300 retail outlets. The ACCC's investigation found that the acquisition of 53 sites by Caltex would be likely to have the effect of substantially lessening competition in the relevant local markets. The sites were in Brisbane, Sydney, Melbourne and Adelaide, the cities on which the ACCC analysis was focused. The ACCC was also concerned that the takeover would exacerbate co-ordination in retail petroleum markets, most particularly because Caltex is frequently a price leader when prices cycle upwards, and Mobil has, on average, lower prices than Caltex. In its press release, the ACCC expressed a preference that the retail outlets be taken over by a 'maverick' or aggressive discounter more likely to inject competition into the marketplace.

In undertaking its analysis, the ACCC looked at overall price levels in each of the cities analysed, determining which brands had the lowest prices. It also examined local market effects. It defined a local market as all the outlets within five kilometres of the outlet being analysed. It looked at idiosyncratic features of each local market, such as local geography and the number and nature of independent operators in each market, but its main focus was the market share of outlets controlled by Caltex before and after the merger. If this post-merger share was greater than 50 per cent, the ACCC suggested this would be likely to

3 Our approach could be easily replicated for any of the cities which the ACCC does analyse by someone with the Informed Sources datasets that the ACCC used in its analysis. We do not have access to these data, so 
result in competition concerns in that local marketplace, whilst for proportions between 40 and 50 per cent it suggested that the takeover may raise competition concerns. It was on the basis of this assessment that the ACCC made its decision.

Perth was not included in the ACCC's decision. However, it has excellent data that we have used to explore market structure and its effects on pricing (see Bloch and Wills-Johnson 2010a, b, c, d). Thus, in this paper, we compare and contrast the ACCC's methodology with our own by applying both to the Perth market. First, we describe in detail the Perth market and our methodology for determining market structure.

\section{Background to the Perth Market}

Retail petroleum outlets in Western Australia are governed by the FuelWatch scheme, whereby each outlet must advise the regulator (who publicises that price) of its next-day price and keep that price for 24 hours. The regime is described in detail in ACCC (2007) and controversies surrounding analysis of its impacts are discussed in Davidson (2008).

The data used in this study cover the period from 1st January 2003 to 14th March 2004. The start date is chosen as data on wholesale or terminal gate prices (the proxy for the marginal cost of retailers) are unavailable before this date, and the end date is chosen because the following day marked the conversion of some 40 Shell outlets into Coles Express outlets through a joint venture between Coles and Shell. The data do not cover all outlets in Perth, omitting some on the outskirts of the city, those for which the data series are incomplete (usually because they are new, or were closed for long periods during the sample period owing to a change in ownership) and those for which the retailing of fuel is not a core business (such as taxi depots and marinas). Data on demand come from the ABS Census (ABS 2006), whilst the remaining data come from FuelWatch, or are based on data in the Fuel Watch database. ${ }^{4}$

Table 1 provides information on branding, ownership structures, the presence of convenience stores and location of competitors. Caltex has the largest number of stations, followed by BP and Shell. Independent chains (Gull, Liberty and Peak) make up roughly a quarter of the sample, making them collectively more important than Shell and slightly smaller than BP. Mobil is a relatively small player in the market, helping to explain why Perth was left out of the ACCC examination. Supermarkets are more prevalent today than in the dataset, which precedes the entry of Coles and is from a time when only a small number of Woolworths outlets existed. Today, the two comprise almost half of overall fuel sales in Australia (ACCC 2007). 
Company-controlled outlets comprise roughly half of those in Table 1, according to FuelWatch, which defines outlets owned directly by the Majors and outlets owned by their multi-site franchisees as being company-controlled. In WA as a whole, Shell owns eight sites, BP owns five and Mobil none. Thus, most of the outlets listed as company-controlled in Table 1 are owned by one of the multisite franchisees. Caltex has no multi-site franchises due to the terms of its 1995 merger with Ampol (see Walker and Woodward 1996). Instead, it uses singlesite franchises and a price-support scheme described in detail in Wang (2009).

Table 1: Perth market summary (2003-2004)

\begin{tabular}{|c|c|c|c|c|c|c|c|c|}
\hline \multicolumn{3}{|l|}{ Branding } & \multirow{2}{*}{\multicolumn{2}{|c|}{ Ownership }} & \multicolumn{2}{|c|}{$\begin{array}{l}\text { Competitors within } \\
5 \mathrm{~km}\end{array}$} & \multicolumn{2}{|c|}{$\begin{array}{l}\text { Distance to nearest } \\
\text { competitor }\end{array}$} \\
\hline & Total & $\begin{array}{l}\text { With Con- } \\
\text { venience } \\
\text { Store }\end{array}$ & & & $\begin{array}{l}\text { Number of } \\
\text { competitors }\end{array}$ & Frequency & $\begin{array}{l}\text { Distance } \\
(\mathrm{km})\end{array}$ & Frequency \\
\hline BP & 52 & 16 & $\begin{array}{l}\text { Branded } \\
\text { Independent }\end{array}$ & 23 & up to 2 & 10 & $\begin{array}{l}\text { up to } \\
0.4\end{array}$ & 38 \\
\hline Caltex & 57 & 29 & $\begin{array}{l}\text { Company- } \\
\text { controlled }\end{array}$ & 99 & 3 or 4 & 16 & $\begin{array}{l}0.41 \text { to } \\
0.8\end{array}$ & 38 \\
\hline Woolworths & 4 & & $\begin{array}{l}\text { Distributor- } \\
\text { controlled }\end{array}$ & 2 & 5 or 6 & 31 & $\begin{array}{l}0.81 \text { to } \\
1.2\end{array}$ & 41 \\
\hline Gull & 27 & & Independent & 2 & 7 or 8 & 35 & $\begin{array}{l}1.21 \text { to } \\
1.6\end{array}$ & 35 \\
\hline Independent & 2 & & $\begin{array}{l}\text { Larger } \\
\text { Independent }\end{array}$ & 37 & 9 or 10 & 43 & $\begin{array}{l}1.61 \\
\text { to } 2\end{array}$ & 39 \\
\hline Liberty & 5 & & $\begin{array}{l}\text { Price- } \\
\text { supported }\end{array}$ & 42 & 11 or 12 & 37 & $\begin{array}{l}2.01 \text { to } \\
2.4\end{array}$ & 8 \\
\hline Mobil & 13 & 11 & Supermarket & 4 & 13 or 14 & 13 & $\begin{array}{l}2.41 \text { to } \\
2.8\end{array}$ & 5 \\
\hline Peak & 13 & & & & 15 or 16 & 17 & $\begin{array}{l}2.81 \text { to } \\
3.2\end{array}$ & 2 \\
\hline Shell & 35 & 8 & & & $>16$ & 7 & $>3.2$ & 3 \\
\hline Wesco & 1 & & & & & & & \\
\hline
\end{tabular}

Convenience stores attached to retail petroleum outlets are often an important source of profits for the brands which own them. Caltex has two conveniencestore brands, whilst Shell, Mobil and BP have one apiece. Most Mobil outlets have a convenience store attached, as do around two-thirds of Caltex outlets. The shares for BP and Shell are each less than one-third. None of the independent brands has a convenience-store brand, though some (Gull, in particular) sell convenience-store items in many of their outlets.

Perth is a relatively low-density city and retail petroleum outlets tend to be located along highways or at the major shopping centres which exist in some suburbs. This is in part due to zoning laws and in part due to a desire to be located at nodes of demand. For this reason, distance to the nearest rival tends to be low (on average just over one $\mathrm{km}$ ) and the average number of competitors within five kilometres is nine. 


\section{The Perth Market as a Network for Spatial Competition}

An important aspect of this paper is the way in which we model competition. Rather than use an indirect measure, such as seller density, or the penetration of independents, we develop a simple theoretical model of bilateral interaction. We collect these bilateral links to form a network that summarises the structure of competition in the marketplace as a whole and use simple graph-cutting tools to delineate local sub-markets. We then use a number of measures of network structure taken from the geography and mathematical sociology literature, especially Gould (1967) and Burt (1992), respectively, to summarise the position of each retail petrol outlet in the overall structure of the global market and local sub-markets. We describe the process of network formation and division briefly below, and in more detail in Bloch and Wills-Johnson (2010c).

We start with a simple theoretical model of spatial competition based upon the work of Hoover (1937) and MacBride (1983), who study how spatial differentiation can give rise to local market power. Our point of departure is an assumption that consumers come to the retailer rather than having goods delivered to them. This requires the retailer to set a single price for all consumers.

Our model is of a duopoly where each firm sells one unit of an homogenous good to an homogenous set of consumers whose travel plans take them past one retail petroleum outlet, but who must deviate to frequent the other (meaning purchase from the former is costless but that from the latter is not). Each firm can match the price of its rival, set a higher price and collect rents from those customers for whom deviation to its rival is more costly or set a price lower than its rival and endeavour to steal market share. Bloch and Wills-Johnson (2010a) show situations whereby this will give rise to an Edgeworth Cycle in prices. ${ }^{5}$ Further, the minima of such price cycles are related across firms in a consistent fashion, with the minimum of each price cycle for each outlet in the duopoly the same if marginal costs and the proportion of consumers passing each outlet first are equal (for an illustration of this result, see Bloch and Wills-Johnson 2010c).

The spatial-competition model suggests a simple measure of connection. We first form the series of price cycle minima for each petrol station by taking its lowest price in the three days prior to each price increase of greater than five per cent. ${ }^{6}$ We then undertake a simple statistical test of the difference between the means for each pair of outlets within five kilometres of one another. ${ }^{7}$

\footnotetext{
5 An Edgeworth Cycle in prices is a pattern in which a substantial rise in price is followed by a series of small price decreases that more or less offset the original rise in magnitude.

6 Looking four days prior and using different magnitude of price increases makes little difference to results; the increasing phase of each price cycle is quite clear in the data.

7 The ACCC adopts this local market definition in a recent merger decision (see http://www.accc.gov.au/ content/index.phtml/itemId/904296), and a similar distance is used to define local markets in the US literature
} 
Where there is no statistically significant difference between the means, we deem the two outlets to be connected. ${ }^{8}$ By collecting these connected pairs, we are able to construct a network that summarises the patterns of connection in the overall market.

We divide this network into a series of sub-markets, using an approach pioneered by Gould (1967), and subsequently widely used in geography (see, for example, Cliff, Haggett and Ord 1979; Boots 1985; O'hUallachain 1985; and Straffin 1980). The network is first converted into an adjacency matrix; a symmetric, zeroone matrix where a zero in the ijth position indicates that nodes $i$ and $j$ are not connected, and a one indicates that they are. This adjacency matrix contains information about the connections between markets, but is unwieldy (the matrix for all stations in the Perth market has 208 rows and columns). Instead, we utilise information contained in the eigenvectors of this adjacency matrix. ${ }^{9}$ The first eigenvector of the adjacency matrix (that is, the eigenvector associated with the largest eigenvalue) has all positive entries, while the remaining eigenvectors contain positive and negative elements. We follow Gould (1967) in taking clusters of positive and negative eigenvector elements as indicating association in pricing and use these clusters as sub-groups within the network. The approach is somewhat judgemental, but Bloch and Wills-Johnson (2010c) show sub-markets thus created give a better characterisation of groups of likepriced outlets than does, for example, branding.

Figure 1 shows the eight sub-markets that result from dividing the market into sub-markets using clusters in the second to sixth eigenvectors (after which the signal to noise ratio makes it impossible to uncover further structure). The dark-grey area represents the Swan River, which divides the city North from South, and the light grey line represents the main north-south freeway, which divides East from West. Placement of each station is approximate, but roughly correlates to the physical shape of the Perth market. ${ }^{10}$ The different shaded dots represent different brands.

Having constructed the network and divided it up into sub-markets, a number of summary statistics can be calculated for the network as a whole and for each sub-market in isolation. Of particular use are Burt's (1992) measures of efficiency

(see Hastings 2004 or USSPSICGA 2002). We use it as a provisional measure of local markets, to avoid having to test every possible bilateral pair out of 208 petrol stations.

8 As noted by an anonymous referee, having prices that move together need not imply that two stations are in competition. They could just as well be colluding over price. Thus, we use the term 'connected', and appraise the matter empirically. In the results of the statistical analysis of price movements, which are summarised below, price matching is associated with higher prices during downswings in the price cycle, suggesting collusion.

9 Eigenvectors have special properties that are useful for organising the information in a matrix of values. In particular, pre and post multiplying a matrix by the matrix of its eigenvectors results in a matrix containing the eigenvalues along the diagonal. For a definition of eigenvectors and a discussion of their properties see, for example, Johnston and DiNardo 1997: 476-83. 
and constraint, which have been widely used in the literature on networks, and Burt (2000, 2002 and 2005) contain reviews of empirical applications of his measures.

The efficiency of the network for a given node is its effective size divided by $N$ ( $N$ being the number of stations in the sub-market), where the effective size of the network for the node is the sum of the direct connections to other nodes in the network. The effective size ranges from one to $N$, so efficiency ranges from zero to one. In the context of a network of retail petrol stations, efficiency provides a measure of the proportion of direct connections between stations in the network as opposed to the number of connections that are indirect.

Constraint for a node is the extent to which a node that severs its direct connection with another node still has indirect connections. Burt's (1992) measure of constraint increases with the number of redundant connections in a network. The more indirect are the connections between two nodes, the more redundant are these connections, as there are then many paths down which information can flow between the stations.

Elsewhere (Bloch and Wills-Johnson 2010d), we regress Burt's measures of efficiency and constraint, along with a number of other independent variables, against price, using Hansen's (1996, 1999, 2000) Threshold Regression Model to differentiate between effects that dominate in the upwards phase of the price cycle and those which dominate in the downwards phase. We find that global constraint (that is, Burt's constraint score for each node in the network as a whole) has a negative coefficient during the downswing of the cycle, indicating that those outlets that are the bridges between sub-markets, and are hence least constrained, exhibit the highest prices. We also find that local efficiency and local constraint (that is, within each sub-market) have positive coefficients during the downswing. ${ }^{11}$ The former is consistent with the negative global constraint result, and suggests that those outlets for which the relevant local market is favourable are able to leverage their superior structural position into higher prices. ${ }^{12}$ The latter, however, does not fit this same picture. We suspect that what is happening is that the peripheral outlets, with access to customers outside the network in Figure 1, pay less attention to the pricing of their peers in each local market and concentrate instead upon reaping monopoly profits from these external customers for which they face limited competition. ${ }^{13}$

11 None of the market structure effects are significant during the upswing, confirming Wang's (2009) suspicion that it is only in the downswing that local market competitive effects are important.

12 Note that this result implies that stations with direct connections to a larger proportion of the stations in the sub-market tend to have higher prices in the downswing. Remembering that all stations in a sub-market are connected either directly or indirectly, this suggests that directness of connection, which might otherwise be a sign of greater competition, appear empirically as a factor leading to higher prices. Thus, price matching, which is the basis for classifying a link as direct, is associated with a lack of competition as expected if price matching signals collusion.

13 Eckert and West (2005) show that outlets on the peripheries of cities in Canada were less likely to close during the 1990s, pointing to similar effects as noted here. 
Agenda, Volume 18, Number 3, 2011

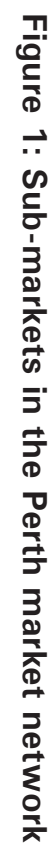

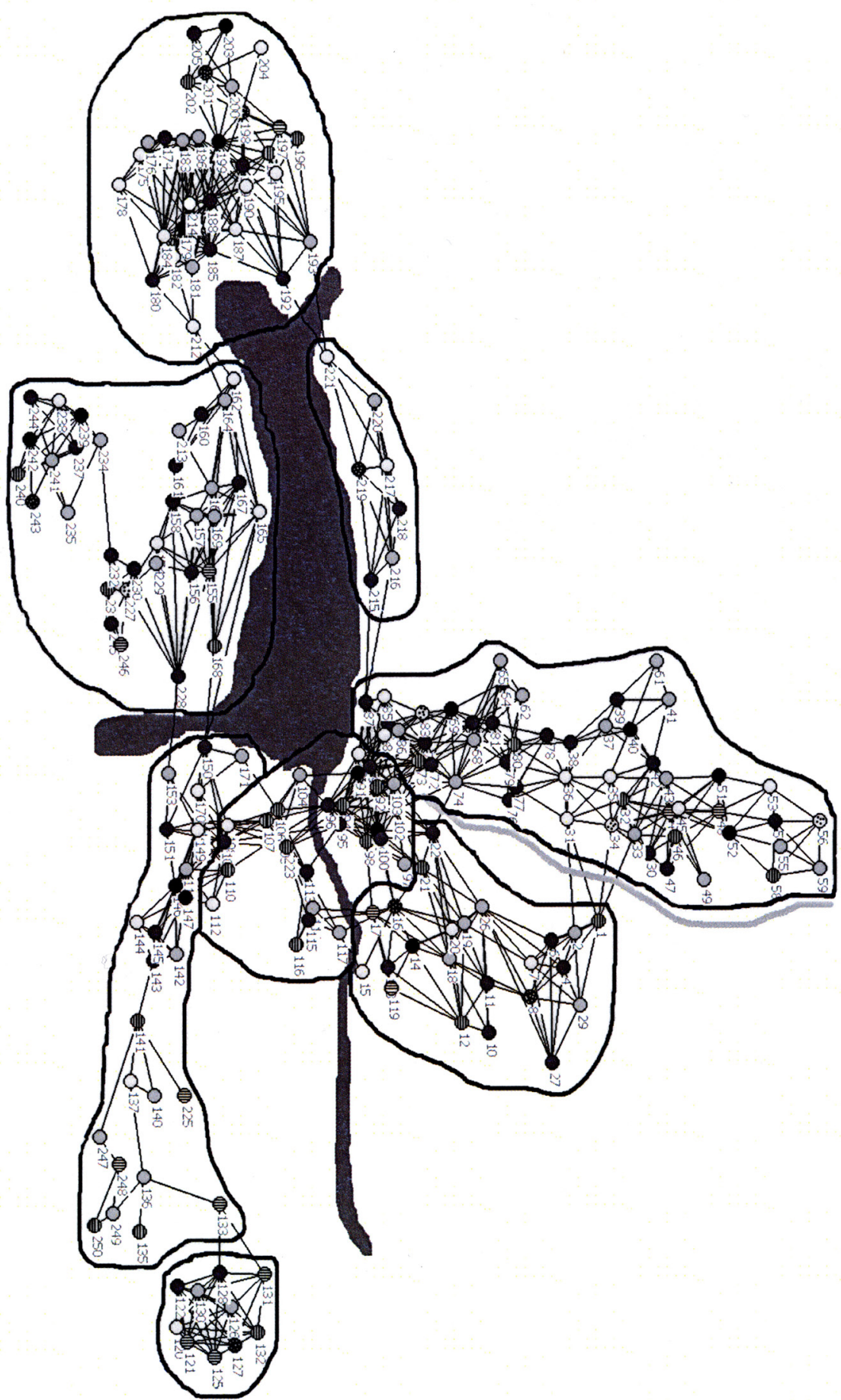




\section{Comparing the Network Approach with the ACCC's Approach}

From the perspective of an assessment of local market competition, therefore, we can now make a number of suggestions. ${ }^{14}$ The first is that the ACCC should look closely at globally unconstrained outlets, which sit at the bridges between sub-markets. If one player can capture many of these in a given market, it may be able to restrict the price linkages between sub-markets, even without owning a majority of outlets in any sub-market.

The second suggestion is that the ACCC should also look at the acquisition of outlets with high local efficiency scores. Possession of sufficient of these in a given local market may provide the relevant owner with sufficient leverage to extract rents from that sub-market without owning a majority of outlets within it.

The third suggestion is that the ACCC should show less concern for the acquisition of outlets on the market fringe. These are likely to have high prices regardless of their ownership. Thus, even if an acquisition of them results in a local market share of greater than one-half, overall competition within that local market is unlikely to be much affected.

Using these lessons, we now compare and contrast an application of the ACCC's methodology in Perth's retail petroleum market with an assessment based upon constraint and efficiency. In Figure 1, there are 13 Mobil outlets. ${ }^{15}$ If we define a local market in the same way that the ACCC does (all outlets within five kilometres of the relevant Mobil outlet) and examine the post-acquisition share of Caltex in each local market, then few competition concerns arise. In only one case (Outlet 69) would the ACCC's threshold of 50 per cent be breached and in only three further cases (Outlets 99, 146 and 147 - with the latter two being essentially the same market) does market share exceed 40 per cent. For the other nine Mobil stations, the ACCC's approach suggests no competition concerns.

\footnotetext{
14 An anonymous referee notes that we have considered only demand aspects of the relationship among stations, excluding consideration of the supply side. We acknowledge this limitation and note that there is only one refinery in the Perth area, which is owned by BP. Limited supplies of refined products are also provided by imports through an independently controlled terminal. Thus, the supply side of the Perth market is highly concentrated. Whether regulation on access and pricing from refineries and import terminals negate the influence of this concentration on retail pricing in the Perth market is an issue beyond the scope of this paper, but one that has been widely discussed in reports by the ACCC and other organisations.

15 There are actually more Mobil stations in Perth, but only these 13 are considered in the analysis of Bloch and Wills-Johnson $(2010 \mathrm{~b}, \mathrm{c}, \mathrm{d})$. Others are on the periphery of the city, or there are insufficient data to undertake econometric analysis.
} 
Agenda, Volume 18, Number 3, 2011

Table 2: Local efficiency in the ACCC's sub-markets for each Mobil station

\begin{tabular}{|c|c|c|c|c|c|c|c|c|c|c|c|}
\hline \multicolumn{2}{|c|}{ Station 14} & \multicolumn{2}{|c|}{ Station 40} & \multicolumn{2}{|c|}{ Station 51} & \multicolumn{2}{|c|}{ Station 52} & \multicolumn{2}{|c|}{ Station 203} & \multicolumn{2}{|c|}{ Station 242} \\
\hline $\begin{array}{l}\text { Stn } \\
\text { No }\end{array}$ & $\begin{array}{l}\text { Eff } \\
\text { Score }\end{array}$ & $\begin{array}{l}\text { Stn } \\
\text { No }\end{array}$ & $\begin{array}{l}\text { Eff } \\
\text { Score }\end{array}$ & $\begin{array}{l}\text { Stn } \\
\text { No }\end{array}$ & $\begin{array}{l}\text { Eff } \\
\text { Score }\end{array}$ & $\begin{array}{l}\text { Stn } \\
\text { No }\end{array}$ & $\begin{array}{l}\text { Eff } \\
\text { Score }\end{array}$ & $\begin{array}{l}\text { Stn } \\
\text { No }\end{array}$ & $\begin{array}{l}\text { Eff } \\
\text { Score }\end{array}$ & $\begin{array}{l}\text { Stn } \\
\text { No }\end{array}$ & $\begin{array}{l}\text { Eff } \\
\text { Score }\end{array}$ \\
\hline 15 & 1 & 40 & 0.625 & 48 & 0.388 & 52 & 0.625 & 204 & 1 & 241 & 0.556 \\
\hline 16 & 0.592 & 42 & 0.556 & 51 & 0.388 & 54 & 0.625 & 201 & 0.52 & 242 & 0.556 \\
\hline 12 & 0.5 & 39 & 0.5 & 52 & 0.36 & 55 & 0.556 & 200 & 0.25 & 235 & 0.5 \\
\hline 14 & 0.469 & 37 & 0.375 & 53 & 0.333 & 48 & 0.5 & 202 & 0.25 & 243 & 0.5 \\
\hline 17 & 0.44 & 41 & 0.375 & 44 & 0.278 & 53 & 0.5 & 203 & 0.25 & 238 & 0.25 \\
\hline 118 & 0.44 & 35 & 0.333 & 45 & 0.278 & 58 & 0.5 & 205 & 0.25 & 239 & 0.25 \\
\hline 18 & 0.389 & 38 & 0.333 & 43 & 0.2 & 51 & 0.36 & & & 240 & 0.25 \\
\hline 119 & 0.375 & 43 & 0.333 & 46 & 0.2 & 44 & 0.25 & & & & \\
\hline 19 & 0.28 & 61 & 0.333 & & & 45 & 0.25 & & & & \\
\hline 20 & 0.28 & & & & & & & & & & \\
\hline
\end{tabular}

\begin{tabular}{|c|c|c|c|c|c|c|c|c|c|c|c|c|c|}
\hline \multicolumn{2}{|c|}{ Station 69} & \multicolumn{2}{|c|}{ Station 91} & \multicolumn{2}{|c|}{ Station 99} & \multicolumn{2}{|c|}{ Station 146} & \multicolumn{2}{|c|}{ Station 147} & \multicolumn{2}{|c|}{ Station 179} & \multicolumn{2}{|c|}{ Station 199} \\
\hline $\begin{array}{l}\text { Stn } \\
\text { No }\end{array}$ & $\begin{array}{l}\text { Eff } \\
\text { Score }\end{array}$ & $\begin{array}{l}\text { Stn } \\
\text { No }\end{array}$ & $\begin{array}{l}\text { Eff } \\
\text { Score }\end{array}$ & $\begin{array}{l}\text { Stn } \\
\text { No }\end{array}$ & $\begin{array}{l}\text { Eff } \\
\text { Score }\end{array}$ & $\begin{array}{l}\text { Stn } \\
\text { No }\end{array}$ & $\begin{array}{l}\text { Eff } \\
\text { Score }\end{array}$ & $\begin{array}{l}\text { Stn } \\
\text { No }\end{array}$ & $\begin{array}{l}\text { Eff } \\
\text { Score }\end{array}$ & $\begin{array}{l}\text { Stn } \\
\text { No }\end{array}$ & $\begin{array}{l}\text { Eff } \\
\text { Score }\end{array}$ & $\begin{array}{l}\text { Stn } \\
\text { No }\end{array}$ & $\begin{array}{l}\text { Eff } \\
\text { Score }\end{array}$ \\
\hline 69 & 0.44 & 91 & 0.511 & 97 & 0.5 & 146 & 0.528 & 147 & 0.521 & 179 & 0.361 & 199 & 0.886 \\
\hline 67 & 0.407 & 97 & 0.5 & 102 & 0.396 & 147 & 0.48 & 146 & 0.48 & 183 & 0.361 & 198 & 0.56 \\
\hline 68 & 0.407 & 104 & 0.5 & 21 & 0.389 & 145 & 0.333 & 111 & 0.375 & 184 & 0.322 & 188 & 0.411 \\
\hline 83 & 0.36 & 90 & 0.449 & 99 & 0.385 & 111 & 0.313 & 145 & 0.333 & 185 & 0.292 & 194 & 0.275 \\
\hline 86 & 0.36 & 92 & 0.404 & 100 & 0.375 & 109 & 0.281 & 109 & 0.265 & 214 & 0.273 & 195 & 0.271 \\
\hline 71 & 0.313 & 89 & 0.347 & 98 & 0.372 & 148 & 0.281 & 110 & 0.265 & 188 & 0.256 & 197 & 0.233 \\
\hline 81 & 0.28 & 102 & 0.347 & 16 & 0.333 & 149 & 0.281 & 112 & 0.25 & 178 & 0.25 & 214 & 0.233 \\
\hline 72 & 0.265 & 103 & 0.333 & 22 & 0.278 & 151 & 0.25 & 142 & 0.2 & 180 & 0.25 & 189 & 0.214 \\
\hline 73 & 0.265 & 73 & 0.309 & 92 & 0.24 & 142 & 0.2 & 143 & 0.2 & 186 & 0.22 & 190 & 0.214 \\
\hline 74 & 0.265 & 98 & 0.309 & 103 & 0.24 & 143 & 0.2 & 144 & 0.2 & 187 & 0.188 & 200 & 0.18 \\
\hline 64 & 0.25 & 96 & 0.306 & 94 & 0.16 & 144 & 0.2 & 148 & 0.167 & 182 & 0.185 & 196 & 0.14 \\
\hline & & 87 & 0.281 & 95 & 0.16 & 110 & 0.184 & 149 & 0.167 & 181 & 0.156 & 181 & 0.1 \\
\hline & & 86 & 0.265 & 96 & 0.16 & 108 & 0.167 & & & 189 & 0.156 & 182 & 0.1 \\
\hline & & 82 & 0.25 & 91 & 0.156 & & & & & 190 & 0.156 & 201 & 0.1 \\
\hline & & 84 & 0.224 & 90 & 0.136 & & & & & & & 202 & 0.1 \\
\hline & & 94 & 0.18 & & & & & & & & & & \\
\hline & & 95 & 0.18 & & & & & & & & & & \\
\hline & & 99 & 0.16 & & & & & & & & & & \\
\hline
\end{tabular}

Note: Existing Mobil outlets are coloured light grey, and Caltex are coloured dark grey.

However, applying a network perspective with Figure 1 gives several reasons for competition concerns. Turning first to global constraint, Outlets 91, 199, 99, 69 and 179 all lie in the lower quartile of global constraint results. This suggests they may be able to use their position vis-à-vis the market as a whole to strategically control the prices that link sub-markets. For example, Outlet 91 
appears to be one of the links for prices between the North and South of the Swan River. Its owner may thus have scope to restrict the link in prices from South to North. Moreover, following a merger, Caltex would control more than a third of these lower-quartile outlets; that is, as much as BP and Shell combined. There may thus be wisdom in excising these outlets from the sale, and requiring that they be purchased by independents, as they might have less interest in controlling the link in prices between sub-markets.

As noted above, local constraint is not an issue, but local efficiency is shown to have an increasing impact on price during the downswing of the price cycle. To explore this further, we calculate the local efficiency scores (the efficiency score for a station within its local sub-market) for each of the outlets in the 13 local markets created by following the ACCC's market definition, and allowing every outlet within five kilometres to be connected. ${ }^{16}$ The results are shown in Table 2.

We do not present any definitive demarcation points, such as possessing more than half the total efficiency, as this would be arbitrary, in much the same way as the ACCC's benchmark of half the market share is. However, in the case of the markets around Outlets 14, 203 and 99, there would appear to be few concerns, as Caltex is not acquiring any of the outlets with the top three efficiency scores. The markets around outlets 242 and 179 are also unlikely to pose much concern as, even though Caltex is acquiring outlets with high efficiency scores, there is not much difference between the largest and smallest scores. The same might be said of Outlet 91. For the remainder, however, Caltex is acquiring the most efficient and/or the second-most efficient outlet. In particular, in the case of Outlet 199, the Mobil outlet is much more efficient that others in its local market, and thus its acquisition may raise concerns, even though Caltex would only have two outlets in that market.

\section{Conclusions}

In its recent decision on the proposed takeover of Mobil's retail sites around Australia by Caltex, the ACCC paid particular attention to the local market effects, examining whether the takeover would put Caltex in a position of having a greater than 50 per cent market share in any local market. This is appropriate if all outlets in a given local market are equal. However, clearly they are not. The ACCC endeavoured to account for this in a rather ad-hoc fashion by

\footnotetext{
16 The result is local markets that are a little more densely connected than the radius of five kilometres around each Mobil outlet in Figure 1 would suggest.
} 
considering idiosyncrasies of each local market, such as the presence or absence of independents or particular geographic features (main roads, for example) that might influence competition.

Here, we present an alternative approach to account for the inequalities between outlets by modelling market structure more directly through the use of networks that are identified by correspondence in pricing behaviour, and considering market power to be related to positioning in that network. We compare and contrast our methodology with the ACCC's own approach, using the retail petroleum market in Perth as a case study. It allows us to highlight two salient points. The first of these is that had the ACCC's assessment included the Perth Mobil outlets, its methods would have missed a number of key outlets that sit at junction points between sub-markets and are thus potentially able to obstruct the linkage in prices between those sub-markets. The second is that, at the level of each local market, one can uncover elements of local market power deriving from the structure of the relevant local market that are missed by the ACCC's approach.

The methodology presented here does not aim to present an infallible or complete picture of market dynamics. However, it does provide a way of capturing competitive behaviour in a formal manner, and bringing this information to bear in market power and merger analyses. Although we use a retail petroleum market as a case study here, the methodology has wide application whenever the competition between firms in a market has a spatial nature.

\section{References}

Australian Bureau of Statistics 2006, 2006 Census of Population and Housing, ABS: Canberra.

Australian Competition and Consumer Commission 2007, Petrol Prices and Australian Consumers: Report of the ACCC inquiry into the price of unleaded petrol, ACCC, Canberra. Retrieved 12th February 2010 from: www.accc.gov. $\mathrm{au} /$ content/index.phtml/itemId/806216.

Bloch, H. and Wills-Johnson, N. 2010a, 'A Simple Spatial Model for Edgeworth Cycles', Economics Letters 108: 334-36.

2010b, The Shape and Frequency of Edgeworth Price Cycles in an Australian Retail Gasoline Market, SSRN Working Paper 1558747. Retrieved 25th February 2010 from: <http://ssrn.com/abstract=1558747>. 
2010c, Retail Gasoline Markets as Networks, SSRN Working Paper 1558748. Retrieved 25th February 2010 from: <http://ssrn.com/ abstract $=1558748>$.

2010d, Gasoline Price Cycle Drivers: An Australian Case Study, SSRN Working Paper 1558766. Retrieved 25th February 2010 from: <http://ssrn. com/abstract $=1558766>$.

Boots, B. N. 1985, 'Size effects in the spatial patterning of non-principal eigenvectors of planar networks', Geographical Analysis 17(1): 74-81.

Borgatti, S. P., Everett, M. G. and Freeman, L. C. 2002, Ucinet for Windows: Software for Social Network Analysis, Analytic Technologies: Harvard, Massachusetts.

Burt, R. S. 1992, Structural Holes: The Social Structure of Competition, Harvard University Press: Cambridge Massachusetts.

2000, 'The Network Structure of Social Capital', in R. I. Sutton and B. M. Staw, Research in Organizational Behavior 22: 345-423, Elsevier Science, Greenwich, Connecticut.

2002, 'The Social Capital of Structural Holes', in Guillen, M. F., Collins, R., England, P. and Meyer, M., The New Economic Sociology: Developments in an emerging field, Russell Sage, New York: 148-90.

2005, Brokerage and Closure: An Introduction to Social Capital, Oxford University Press: Oxford.

Cliff, A. D., Haggett, P. and Ord, J. K. 1979, 'Graph Theory and Geography', in Wilson, R. J. and Beineke, L. W., Applications of Graph Theory, Academic Press, London: 293-326.

Davidson, S. 2008, 'Secret econometric business: Watching Fuelwatch and the ACCC', Agenda 15(4): 5-18.

Eckert, A. and West, D. S. 2005, 'Rationalization of retail gasoline station networks in Canada', Review of Industrial Organization 26(1): 1-25.

Gould, P. 1967, 'The geographical interpretation of eigenvalues', Transactions of the Institute of British Geographers 42: 53-85.

Hansen, B. E. 1996, 'Inference when a nuisance parameter is not identified under the null hypothesis', Econometrica 64(2): 413-30.

1999, 'Threshold effects in non-dynamic panels: Estimation, testing and inference', Journal of Econometrics 93: 345-68. 

575-603.

Hastings, J. 2004, 'Vertical relationships and competition in retail gasoline markets: Empirical evidence from contract changes in Southern California', American Economic Review 94(1): 317-28.

Hoover, E. M. 1937, 'Spatial price discrimination', Review of Economic Studies 4(3): 182-91.

Johnston, J. and DiNardo, J. 1997, Econometric Methods, McGraw Hill, New York.

McBride, M. E. 1983, 'Spatial competition and vertical integration: Cement and concrete revisited', American Economic Review 73(5): 1011-22.

O'hUallachain, B. 1985, 'Complementary linkages and the structure of regional economies', Geographical Analysis 17(2): 130-42.

Straffin, P. D. 1980, 'Linear algebra in geography: Eigenvectors of networks', Mathematics Magazine 53(5): 269-76.

Thill, J. C. 1998, 'A note on the matrix formulation of gerrymanders', Environment and Planning B: Planning and Design 25: 495-505.

United States Senate Permanent Subcommittee on Investigations: Committees of Government Affairs (USSPSICGA) 2001, Gas Prices: How are they really set? Retrieved 12th February 2010 from: http://www.gpo.gov/congress/senate/ senate12sh107.html.

Walker, J. and Woodward, L. 1996, 'The Ampol/Caltex Australia merger: Trade practices issues', Trade Practices Law Journal 4: 21-48.

Wang, Z. 2009, '(Mixed) strategy in oligopoly pricing: Evidence from gasoline price cycles before and under a timing regulation', Journal of Political Economy 117(6): 987-1030. 